\section{MPL Y252H and MPL F126fs mutations in essential thrombocythemia: Case series and review of literature}

\author{
Ahmed G. Elsayed, ${ }^{1}$ Aeesha Ranavaya, ${ }^{2}$ \\ Muhammad Omer Jamil ${ }^{2}$ \\ ${ }^{1}$ Hematology Oncology Department, \\ Promedica/University of Toledo, Toledo, \\ OH; ${ }^{2}$ Hematology/Oncology \\ Department, Joan C. Edwards School of \\ Medicine, Marshall University, WV, \\ USA
}

\begin{abstract}
Essential thrombocythemia (ET) is a clonal bone marrow disease, characterized by increased production of platelets along with other clinical and bone marrow findings. Most patients with ET will have a somatic mutation in one of the known gene locations of $J A K 2, C A L R$, or $M P L$ that can upregulate the JAK-STAT pathway. $M P L$ mutation is present in $5 \%$ of cases with the most common mutations being $W 515 \mathrm{~L}$ and $W 515 K$. In this report we describe 2 cases of patients with clinical and laboratory picture of ET. One patient carried MPLY252H mutation which is previously unreported in the adult population but has been shown to be a gain-of-function mutation. The other patient carried MPL F126fs mutation which is not known to be of clinical importance and has not been previously reported.
\end{abstract}

\section{Introduction}

Essential thrombocythemia (ET) is a clonal bone marrow disease, characterized by increased production of platelets. Most patients with ET will have a somatic mutation in Janus Kinase 2 (JAK2), Calreticulin $(C A L R)$, or myeloproliferative leukemia virus oncogene $(M P L)$ with subsequent upregulation of the JAK-STAT pathway. $J A K 2 \mathrm{~V} 617 \mathrm{~F}$ activating mutation is present in $50-60 \%$ of ET cases, CALR mutation is present in $20-25 \%$ of cases, while $M P L$ mutation is present in $5 \%$ of cases. Patients who lack all three mutations are usually called triple negative. The most common mutations in $M P L$ are $W 515 L$ and $W 515 K{ }^{1}$ Other mutations were also reported such as $S 505 N$, W515A and W515R. We hereby report 2 cases of patients with clinical and laboratory picture of ET who carried 2 mutations that are previously unreported in the adult population.

\section{Case Report \#1}

A 55-year-old female with a past medical history of hypertension, osteoarthritis, neuropathy, and hyperlipidemia presented in consultation for thrombocytosis. She has had thrombocytosis for 8 years prior to presentation. Her laboratory exam showed a platelet count of $558 \mathrm{k}$, white blood cell counts of $9.2 \mathrm{k}$, and hemoglobin of $12.9 \mathrm{gm}$. She reported having occasional headaches and blurry vision, but was otherwise asymptomatic. Bone marrow biopsy showed mildly hypercellular bone marrow (70\%) showing trilineage hematopoiesis with mildly increased megakaryocytes. She had adequate reticuloendothelial iron, with no ringed sideroblasts. There was no fibrosis on reticulin stain. No evidence of causes of secondary thrombocytosis was found. Molecular studies showed MPLY252H mutation. Other variants found were EP300, MAP3K7, NTRK1, and YY1AP1.

\section{Case Report \#2}

A 50-year-old female with a past medical history of diabetes, rheumatoid arthritis, and COPD was referred for thrombocytosis. Further review of laboratory data revealed that her platelet count has been elevated for 4 years prior to her referral. Platelet counts had been ranging from 518$600 \mathrm{k}$. Patient has been asymptomatic and denied any history of thrombotic event. Patient declined bone marrow biopsy so molecular studies were sent from peripheral blood. Results revealed multiple abnormalities. MPL F126fs*5 mutation was detected. Other variants detected included CSF1R, ERBB4, GPR124, KIT, MUTYH, NFE2L2, PIM1, PTPN6, and RNF43. Patient was prescribed Aspirin $81 \mathrm{mg}$ and has been asymptomatic with stable counts after 1 year of follow up.

\section{Discussion and Conclusions}

ET is a clonal disease characterized by marked thrombocytosis, prominent large to giant megakaryocytes in bone marrow, and absence of other identifiable causes of thrombocytosis. World Health Organization (WHO) diagnostic criteria includes absence of other clonal bone marrow disorders such as chronic myeloid leukemia and other myeloproliferative neoplasms. The demonstration of clonal markers favors the diagnosis. JAK2, CALR and MPL mutations are the most common. Subsequently the JAK-
Correspondence: Ahmed G Elsayed, Flowers Hospital, Medical Office Building II Suite 055, 5308 Harroun Rd

Sylvania, OH 43560, USA.

Tel.: +1.4198246599 - Fax: +1.4198823870.

E-mail: ahmed.elsayed@promedica.org; gamal_masry@yahoo.com

Key words: $M P L$ mutations, Essential thrombocythemia, Myeloproliferative disease, $M P L$ Y252H and MPL F126fs.

Contributions: AGE, Prepared the initial draft, revised the manuscript critically, approved the version to be published and agreed to be accountable for all aspects of the work; AR, Revised the manuscript critically, provided some additions and suggestions for many changes, approved the version to be published and agreed to be accountable for all aspects of the work; MOJ, Revised the manuscript critically, provided some additions and suggestions for many changes, approved the version to be published and agreed to be accountable for all aspects of the work.

Conflict of interest: the authors declare no potential conflict of interest.

Funding: none

Received for publication: 16 September 2018 . Accepted for publication: 15 February 2019.

This work is licensed under a Creative Commons Attribution-NonCommercial 4.0 International License (CC BY-NC 4.0).

(C) Copyright A.G. Elsayed et al., 2019

Licensee PAGEPress, Italy

Hematology Reports 2019; 11:7868

doi:10.4081/hr.2019.7868

STAT pathway gets upregulated with further stimulation to cell growth and hematopoiesis. Some of the triple negative cases will have an unusual mutation in $J A K 2, C A L R$ or $M P L$ on whole gene sequencing. ${ }^{2}$ Other mutations in different genes such as $A S X L 1, T E T 2$, and $C B L$ have been reported in patients with MPN. These can exist with other more common gene mutations and are helpful to establish clonality.

The MPL gene encodes for a transmembrane receptor that is highly expressed in CD34+ hematopoietic cells and in the megakaryocytic lineage. The murine $v$ $M P L$ gene was discovered in 1990. Shortly afterwards its human homolog $c-M P L$ was cloned. ${ }^{3}$ The human c-MPL gene contains 12 exons. The two cytokine receptor domains are encoded for by eight exons (29), the cytoplasmic domain is encoded for by two exons (11-12), and the trans-mem- 
brane domain is encoded for by exon 10 . Exon 1 encodes for signal peptide. ${ }^{3}$ The gene encodes for a 635 amino acid transmembrane domain (CD 110). Binding of thrombopoietin to the extracellular domain for MPL leads to dimerization of the receptor and activation of the JAK-STAT pathway. Figure 1 illustrates the structure of human MPL receptor.

Disruption of the juxtamembrane region of the thrombopoietin receptor MPL leads to receptor activation in the absence of receptor binding by thrombopoietin. ${ }^{4}$ Mutations have been reported in the $M P L$ gene. The MPL W515L mutation has been linked to ET. Transplanting bone marrow cells that express this mutation into mice leads to marked thrombocytosis and splenomegaly, as well as other features associated with MPN. ${ }^{5}$ The MPL W515K mutation was discovered several months after MPL W515L, and was shown to be linked to the clinical picture of myeloproliferative neoplasms. ${ }^{1}$

Beer et al. performed an analysis of molecular data from a large retrospective cohort of unselected patients with ET and Primary myelofibrosis (PMF). The entire $M P L$ coding region in 18 patients with ET and 2 patients with PMF was sequenced. No mutations were found outside exon 10 in this study. Subsequently, $M P L$ exon 10 in granulocyte DNA from 200 patients was sequenced. Of these, 88 had ET and 112 had
PMF. Three patients with ET were found to have mutations. One had the MPL S505N mutation and two carried MPL W515L mutations. Eight out of 112 PMF patients were found to have mutations. One carried the MPL S505N mutation, five carried MPL W515L mutations, and two carried $M P L$ W515K mutations. ${ }^{6}$

MPL W515A and MPL W515R mutations are rare, but they are thought to function like $M P L W 515 K$ and $L$. Given the extremely low mutation rate, the clinical significance is not confirmed. ${ }^{7}$ Other mutations described are A506T, L510P, and A519T. The clinical significance of these mutations is still unclear. ${ }^{8}$

MPL S505N can occur of somatic origin in sporadic cases of ET, but has also been reported along with other MPL mutations in cases with hereditary thrombocythemia (HT). In such cases it is a germline mutation that is inherited in an autosomal dominant pattern. ${ }^{9}$ MPL S505N was found to be associated with an increased risk of thrombosis and subsequently splenomegaly and bone marrow fibrosis. ${ }^{10}$

Further mutations associated with HT include MPL K39N and MPL P106L. MPL $K 39 N$ is a polymorphism reported in African Americans. Screening of more than 400 patients and controls revealed that approximately $7 \%$ of African Americans are heterozygous for this polymorphism and that patients affected had a significantly higher platelets count than controls without the polymorphism. ${ }^{11}$ MPL P106L is another mutation that was associated with familial thrombocytosis. It was discovered in an Arab family when two siblings presented with thrombocytosis. Molecular studies in a sample of 213 people revealed that the prevalence of this mutation is $3.3 \%$ in this cohort of unrelated individuals of Arabic descent. The control group of 193 healthy German individuals had no mutation detected. ${ }^{12}$ The clinical outcome of individuals with these 2 mutations (MPL K39N and $M P L \quad P 106 L)$ is still unknown. Other germline mutations that are felt to be associated with HT are MPL V285E and MPL $R 321 \mathrm{~W}$. These are 2 activating germline mutations in exon 6 of MPL identified in 2016 in cases initially diagnosed as ET $(R 321 \mathrm{~W})$ and PMF (V285E). ${ }^{13}$

MPL T119I, MPL S204F, MPL S204P, and MPL E230G were reported in 2016. All of these mutations lead to constitutive activation of JAK-STAT signaling indicating that they are gain of function mutations. ${ }^{13}$ Interestingly, all these mutations are outside of exon 10. The same report identified a new somatic mutation MPL Y591D in exon 12 in a patient who was initially diagnosed with triple negative ET. This patient, however, developed JAK2 V617F mutation at 5.5 years follow-up. MPLS204P and MPLY591N were reported in 2016 in patients with triple negative ET. Both mutations

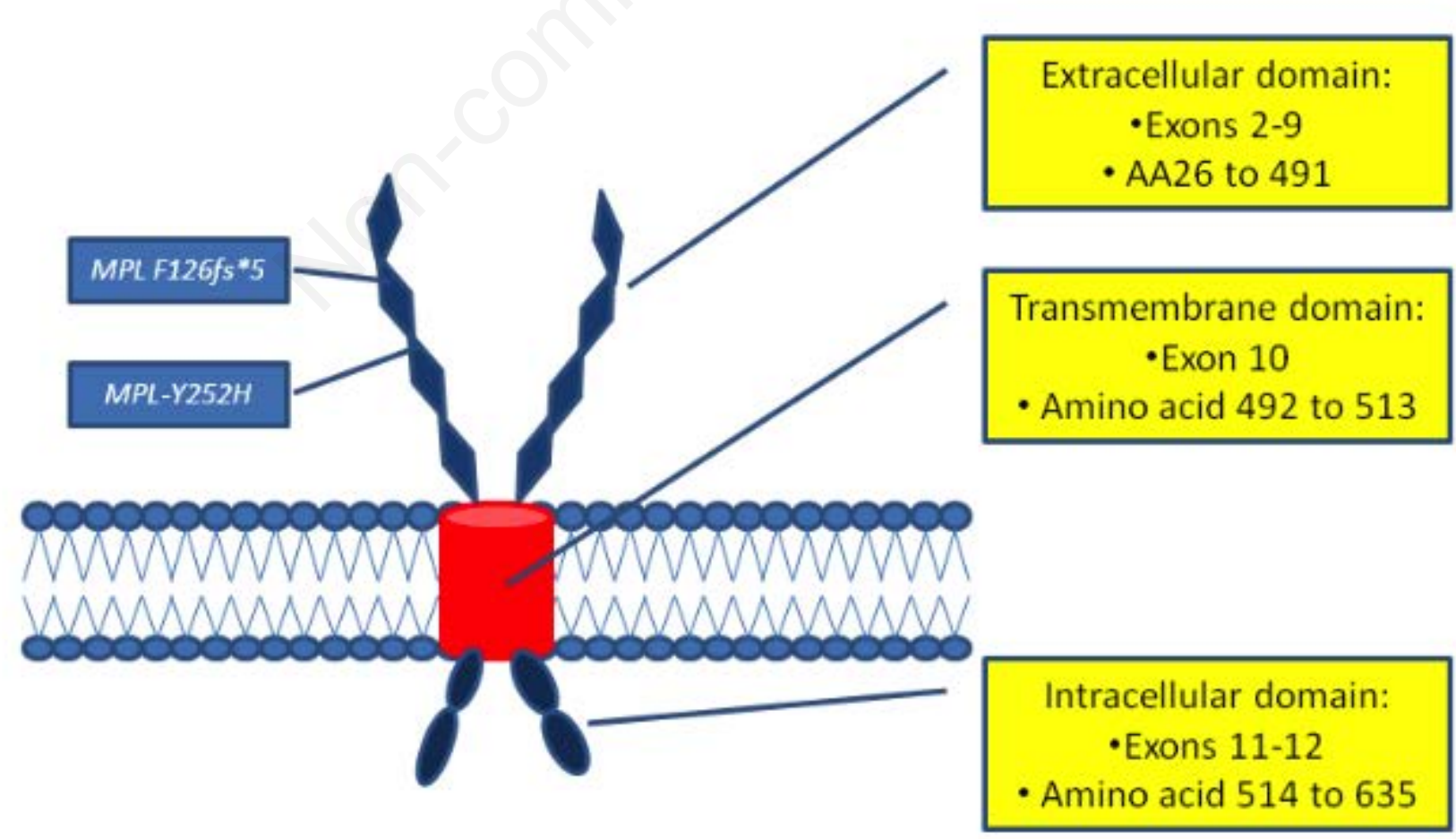

Figure 1. Structure of MPL receptor and location of the 2 reported mutations. Both mutations are in the extracellular domain. 
appeared to be gain of function mutations via in vitro studies ${ }^{14}$ Table 1 summarizes the mutations reported in $M P L$ gene. ${ }^{13-17}$ The MPL Y252H mutation was first described in 2011 in a three-year-old African American female with a JAK2 mutation-negative ET. Exposing bone marrow cells from this patient to thrombopoietin lead to generation of megakaryocyte colonies in vitro. BaF3 cells with the mutation were found to have increased thrombopoietin mediated cell growth and increased cell survival upon cytokine withdrawal. ${ }^{15}$

The MPL Y252H mutation in our case has not been reported in adults before. Based on the work of Lambert et al, this mutation was shown to be a gain of function mutation in the extracellular domain of
MPL. ${ }^{15}$ Our case supports this finding and documents the first reported adult case with clinical picture of ET.

Our second case documents the first clinical case report of a patient with $M P L$ F126fs. This is a frame shift mutation that results in a change in the amino acid sequence of the MPL protein beginning at amino acid 126 of total of 635 . This is

Table 1. Mutations reported in MPL gene.

\begin{tabular}{|c|c|c|c|}
\hline Mutation & type & Clinical effect & Comments [Ref.] \\
\hline K39N & Polymorphism & Familial thombocytosis. & Approximately 7\% of African Americans are heterozygous for this polymorphism [11] \\
\hline P106L & Germline & Familial thrombocytosis & Prevalence was 3.3\% in a cohort of unrelated individuals from Arabic descent [12] \\
\hline T119I & Somatic & $\begin{array}{l}\text { Gain-of-function when analyzed } \\
\text { in functional assays }\end{array}$ & {$[13]$} \\
\hline F126fs $* 5$ & Somatic & & Described in this report in a patient with clinical picture of ET \\
\hline$S 204 F$ & Somatic & $\begin{array}{l}\text { Gain-of-function when analyzed } \\
\text { in functional assays }\end{array}$ & {$[13]$} \\
\hline S204P & Somatic & Weak gain-of-function mutation & [14] \\
\hline E230G & Somatic & $\begin{array}{l}\text { Gain-of-function when analyzed } \\
\text { in functional assays }\end{array}$ & [13] \\
\hline$Y 252 \mathrm{H}$ & Somatic & $\begin{array}{l}\text { Described in } 2011 \text { in a three year old } \\
\text { African American female with a JAK2 } \\
\text { mutation-negative ET }\end{array}$ & Described in an adult patient with ET in this report [15] \\
\hline$V 285 E$ & Germline & Felt to be associated with HT & $\begin{array}{l}\text { Activating germline mutations in exon } 6 \text { identified in } 2016 \text { in a case initially } \\
\text { diagnosed as primary myelofibrosis [13] }\end{array}$ \\
\hline$R 321 W$ & Germline & Felt to be associated with HT & $\begin{array}{l}\text { Activating germline mutations in exon } 6 \text { identified in } 2016 \text { in a case initially } \\
\text { diagnosed as ET [13] }\end{array}$ \\
\hline T487A & Somatic & Acute megakaryoblastic leukaemia & Induces myeloproliferative disorder in mice [16] \\
\hline $\begin{array}{l}\text { T496-A497 } \\
\text { ALVI ins }\end{array}$ & Somatic & Reported in a patient with PMF & [17] \\
\hline V501L & & $\begin{array}{l}\text { Reported in a patient with JAK2 } \\
\text { negative MPN }\end{array}$ & Patient had also $S 505 N$ mutation [17] \\
\hline$S 505 \mathrm{~N}$ & $\begin{array}{l}\text { In most cases } \\
\text { germline mutation }\end{array}$ & Hereditary thrombocythemia & $\begin{array}{l}\text { Inherited in an autosomal dominant pattern, but reported as a somatic mutation } \\
\text { in sporadic cases as well }[9,10]\end{array}$ \\
\hline A506T & Somatic & $\begin{array}{l}\text { Not gain-of-function mutation } \\
\text { based on in vitro studies }\end{array}$ & $\begin{array}{l}\text { Both A506T and A519T mutations were found in a patient with PMF in association with } \\
\text { JAK2 V617F [8] }\end{array}$ \\
\hline V507I & & Reported in a patient with JAK2 negative MPN & [17] \\
\hline L510P & Somatic & $\begin{array}{l}\text { Not gain-of-function mutation based } \\
\text { on in vitro studies }\end{array}$ & [8] \\
\hline$R 514 K$ & & Reported in a patient with JAK2 negative MPN & {$[17]$} \\
\hline $\begin{array}{l}\text { W515L } \\
\text { W515K }\end{array}$ & Somatic & Essential thrombocythemia & Most common mutations in MPL \\
\hline $\begin{array}{l}\text { W515A } \\
\text { W515R }\end{array}$ & Somatic & Essential thrombocythemia & $\begin{array}{l}\text { Given the extremely low mutation rate of W515A/R, the clinical significance } \\
\text { is not confirmed but they are reported to function like W515K/L }\end{array}$ \\
\hline $\begin{array}{l}\text { W515S } \\
W 515 G\end{array}$ & Somatic & Detected in patient with JAK2 negative MPN & {$[17]$} \\
\hline $\begin{array}{l}\text { W515-P518 } \\
\text { delins KT }\end{array}$ & Somatic & MPN & Patient had MPN not otherwise specified [17] \\
\hline A519T & Somatic & $\begin{array}{l}\text { Not gain-of-function mutation based } \\
\text { on in vitro studies }\end{array}$ & $\begin{array}{l}\text { Both A506T and A519T mutations were found in a patient with PMF in association with } \\
\text { JAK2 V617F [8] }\end{array}$ \\
\hline$A 519 \mathrm{~V}$ & & Reported in a patient with JAK2 negative MPN & [17] \\
\hline $\begin{array}{l}R 525 C \\
f s * 14\end{array}$ & Somatic & $\begin{array}{l}\text { Patient had confirmed chronic MPN } \\
\text { not otherwise specified }\end{array}$ & $\begin{array}{l}\text { Exon } 11 \text { mutation involving a deletion of } 2 \text { nucleotides (AG) and insertion of } \\
\text { T with subsequent frameshift and a stop codon after } 13 \text { amino acids [17] }\end{array}$ \\
\hline $\begin{array}{l}D 545 G \\
D 545 N\end{array}$ & Somatic & Reported in a patient with JAK2 negative MPN & Exon $11[17]$ \\
\hline Y591D & Somatic & ET & $\begin{array}{l}\text { Found on exon } 12 \text { in a patient who was initially diagnosed with triple negative ET. } \\
\text { This patient, however, developed JAK2 V617F mutation at } 5.5 \text { years follow-up [13] }\end{array}$ \\
\hline$Y 591 N$ & Somatic & Weak gain-of-function mutation & {$[14]$} \\
\hline
\end{tabular}


expected to result in a premature truncation of the functional protein leading to loss of functional domains, which would lead to loss of function. It is interesting that our case documents the occurrence of a clinical picture consistent with ET in a patient with this mutation.

\section{References}

1. Pardanani AD, Levine RL, Lasho T, et al. MPL515 mutations in myeloproliferative and other myeloid disorders: a study of 1182 patients. Blood 2006;108:3472-6.

2. Abdel-Wahab O, Manshouri T, Patel J, et al. Genetic analysis of transforming events that convert chronic myeloproliferative neoplasms to leukemias. Cancer Res 2010;70:447-52.

3. Mignotte V, Vigon I, Boucher de Crèvecoeur E, et al. Structure and transcription of the human c-mpl gene (MPL). Genomics 1994;20:5-12.

4. Staerk J, Lacout C, Sato T, et al. An amphipathic motif at the transmembrane-cytoplasmic junction prevents autonomous activation of the thrombopoietin receptor. Blood 2006;107: 1864-71.

5. Pikman Y, Lee BH, Mercher T, et al. MPLW515L is a novel somatic activating mutation in myelofibrosis with myeloid metaplasia. PLoS Med 2006;3:e270.

6. Beer PA, Campbell PJ, Scott LM, et al. MPL mutations in myeloproliferative disorders: analysis of the PT-1 cohort. Blood 2008;112:141-9.

7. Schnittger S, Bacher U, Haferlach C, et al. Characterization of 35 new cases with four different MPLW515 mutations and essential thrombocytosis or primary myelofibrosis. Haematologica 2009;94:141-4.

8. Chaligné R, Tonetti C, Besancenot R, et al. New mutations of MPL in primitive myelofibrosis: only the MPL W515 mutations promote a G1/S-phase transition. Leukemia 2008;22:1557-66.

9. Ding J, Komatsu H, Wakita A, et al. Familial essential thrombocythemia associated with a dominant-positive activating mutation of the c-MPL gene, which encodes for the receptor for thrombopoietin. Blood 2004;103:4198200 .

10. Teofili L, Giona F, Torti L, et al. Hereditary thrombocytosis caused by MPLSer505Asn is associated with a high thrombotic risk, splenomegaly and progression to bone marrow fibrosis. Haematologica 2010;95:65-70.

11. Moliterno AR, Williams DM, Gutierrez-Alamillo LI, et al. Mpl Baltimore: a thrombopoietin receptor polymorphism associated with thrombocytosis. Proc Natl Acad Sci USA 2004;101:11444-7.

12. El-Harith e-H, Roesl C, Ballmaier M, et al. Familial thrombocytosis caused by the novel germ-line mutation p.Pro106Leu in the MPL gene. Br J Haematol 2009;144:185-94.

13. Milosevic Feenstra JD, Nivarthi $H$, Gisslinger $\mathrm{H}$, et al. Whole-exome sequencing identifies novel MPL and JAK2 mutations in triple-negative myeloproliferative neoplasms. Blood 2016;127:325-32.

14. Cabagnols X, Favale F, Pasquier F, et al. Presence of atypical thrombopoietin receptor (MPL) mutations in triple-negative essential thrombocythemia patients. Blood 2016;127:333-42.

15. Lambert MP, Jiang J, Batra V, et al. A novel mutation in MPL (Y252H) results in increased thrombopoietin sensitivity in essential thrombocythemia. Am J Hematol 2012;87:532-4.

16. Malinge S, Ragu C, Della-Valle V, et al. Activating mutations in human acute megakaryoblastic leukemia. Blood 2008;112:4220-6.

17. Ma W, Zhang X, Wang X, et al. MPL mutation profile in JAK2 mutation-negative patients with myeloproliferative disorders. Diagn Mol Pathol 2011;20: 34-9. 